\title{
ANALISIS DILATASI WAKTU BERDASARKAN PERSPEKTIF SAINS DAN AL-QUR'AN BERBASIS VIDEO DENGAN MODEL POE2WE
}

Riza Hasanudin ${ }^{1}$, Nana $^{2}$, dan Dwi Sulistyaningsih ${ }^{3}$

1,2,3Pendidikan Fisika FKIP Universitas Siliwangi, Kota Tasikmalaya, Indonesia

Corresponding author email: rizahasanudin2000@gmail.com

Info Artikel

Diterima:

28 Desember 2020

Disetujui:

19 Juni 2021

Dipublikasikan:

30 Juni 2021

\begin{abstract}
Abstrak:
Tujuan penelitian ini untuk mengetahui penjelasan dilatasi waktu menurut teori sains dan Al-Qur'an, serta menganalisis penerapan video dengan model POE2WE. Penelitian ini menggunakan metode deskriftif kualitatif dengan teknik kajian pustaka. Hasil penelitian ini menujukan bahwa menurut teori sains dilatasi waktu merupakan perbedaan waktu akibat gerak relative. Dua pengamat yang bergerak relatif terhadap satu sama lain akan mengalami perbedaan waktu. Di dalam beberapa ayat Al-Qbur'an Allah menjelaskan bahwa satu hari yang menurut Allah sama dengan seribu tahun menurut perhitungan manusia. Hal ini menunjukkan bahwa sebelum Einstein menemukan teori relativitas, Al-Qur'an sudah sejak dulu menjelaskan fenomena tersebut. Penerapan video dengan model POE2WE dalam pembelajaran fisika materi dilatasi waktu sangat cocok diterapkan. Video disajikan dengan menarik sehingga tidak membosankan dan tidak berpusat pada guru sebagai sumber informasi.
\end{abstract}

Kata kunci: Dilatasi waktu, sains, Al-Qur'an, POE2WE

\begin{abstract}
:
The purpose of this study is to find out the explanation of time dilation according to scientific theory and the Qur'an, and to analyze the application of video with the POE2WE model. This study uses a qualitative descriptive method with a literature review technique. The results of this study indicate that according to scientific theory time dilation is the time difference due to relative motion. Two observers moving relative to each other will experience a time difference. In several verses of the Qur'an Allah explains that one day according to Allah is equal to a thousand years according to human calculations. This shows that before Einstein discovered the theory of relativity, the Qur'an had long explained the phenomenon. The application of video with the POE2WE model in time dilation physics learning material is very suitable to be applied. The videos are presented in an interesting way so that they are not boring and are not centered on the teacher as a source of information.
\end{abstract}

Keywords: Time dilation, science Al-Qur'an, POE2WE

Copyright $@ 2021$ Edufisika: Jurnal Pendidikan Fisika

\section{Pendahuluan}

Seiring berkembangnya zaman ilmu pengetahuan banyak sekali mengalami perkembangan, banyak ilmu pengetahuan yang telah mengungkap misteri-misteri di alam semesta ini. Salah satu cabang ilmu pengetahuan yang banyak mengukap realitas alam semesta adalah fisika. Fisika adalah ilmu yang mempelajari berbagai gejala alam. Menurut Mundilarto (2010), fisika sebagai ilmu dasar memiliki karakteristik yang mencakup bangun ilmu yang terdiri atas fakta, konsep, prinsip, hukum, 
postulat, dan teori serta metodologi keilmuan. Sedangkan menurut Wartono (2003) Fisika adalah bangun pengetahuan yang menggambarkan usaha, temuan, wawasan dan kearifan yang bersifat kolektif dari umat manusia. Fisika erat kaitannya dengan proses sains, menurut Alkani (Mahmudah dkk, 2019) proses sains berperan untuk melakukan penyelidikan ilmiah, menemukan konsep, prinsip, juga teori untuk mengembangkan konsep yang sudah ada sebelumnya.

Sejalan dengan berkembangnya ilmu pengetahuan dan teknologi banyak teori-teori dan fakta ilmiah yang sebenarnya sudah dijelaskan didalam kitab suci Al-Qur'an jauh sebelum fakta-fakta ilmiah tersebut ditemukan oleh para ilmuan. Menurut Nana (2019) Pada era digital atau era informasi sekarang ini ilmu pengetahuan dan teknologi berkembang dengan pesat. Perkembangan ini memiliki dampak semakin terbuka dan tersebarnya informasi dan pengetahuan dari dan ke seluruh dunia menembus batas jarak, tempat, ruang dan waktu. Kenyataannya dalam kehidupan manusia di era digital ini akan selalu berhubungan dengan teknologi. Teknologi pada hakikatnya adalah proses untuk mendapatkan nilai tambah dari produk yang dihasilkannya agar bermanfaat.

Kitab suci Al-Qur-an adalah pedoman bagi umat manusia. Menurut Mulyono (2006), AlQur'an merupakan mukjizat yang bersifat abadi dan bersifat ilmiah yang sebenarnya mengajak kepada setiap pembacanya untuk membahas, mengkaji dan meneliti ayat-ayat dalam rangka menemukan hakikat keilmiahan yang ditetapkan sebagai ilmu. Sedangkan menurut Jumini (2015), Al-Qur'an mampu menegaskan kebenaran dan kesesuaiannya terhadap apa yang dihasilkan oleh penemuanpenemuan ilmu pengetahuan yang bersifat kontemporer setelah ratusan tahun ditemukan oleh para pakar dengan kajian, pembahasan dan penalaran.

Kehidupan manusia sangat terikat dengan waktu, bahkan tanpa disadari waktu telah mengatur hidup manusia, persoalan waktu tersebut kini telah dijelaskan dalam salah satu cabang ilmu fisika yang dikenal dengan fisika modern. Fisika modern berkembang karena banyak fenomena-fenomena yang tidak dapat dijelaskan berdasarkan fisika klasik. Persoalaan waktu tersebut dikemukakan oleh seorang ilmuan asal Jerman bernama Albert Einstein dalam salah satu teorinya yaitu teori relativitas khusus, dalam teorinya tersebut ia memandang bahwa waktu itu bersifat relative terhadap titik acuan. Pernyataan tersebut dikenal dengan istilah dilatasi waktu yang merupakan konsekuensi dari teori relativitas khusus. Pada awalnya sebagai ilmuan sains menganggap bahwa waktu itu bersifat absolut yang tidak terbatas. Anggapan tersebut banyak orang yang mempercayai karena memang manusia tidak ada yang tahu secara pasti kapan waktu itu bermula dan kapan waktu itu berakhir, hanya tuhan yang tahu dan menjadi rahasia-Nya. Dilatasi waktu sendiri dipelajari dalam Bab Relativitas di SMA kelas XII.

Salah satu permasalahan dalam pembelajaran fisika berbasis video di sekolah adalah ketidakjelasan model pembelajaran yang digunakan dalam pembelajaran tersebut, dan banyak yang terkesan seperti menggunakan metode ceramah saja yang dikemas dalam bentuk video pembelajaran, sehingga pembelajaran cenderung monoton dan membosankan. Oleh karena itu diperlukan penerapan suatu model pembelajaran yang tidak hanya berpusat pada guru agar video pembelajaran yang dibuat tidak monoton dan tujuan pembelajaran dapat tercapai dengan baik serta peserta didik mampu mengkontruksi pemahaman secara mandiri. Salah satu model pembelajaran yang berpusat pada peserta didik adalah model pembelajaran POE2WE. Menurut Nana, dkk (2014) Model pembelajaran POE2WE merupakan pengembangan dari model pembelajaran POE, model pembelajaran TTW, dan model pembelajaran konstruktivis. Sintaks model POE2WE adalah memprediksi (Prediction), mengobservasi (Observation), menjelaskan (Explanation), elaborasi (Elaboration), menulis (Write), dan mengevaluasi (Evaluation).

\section{Metode Penelitian}

Penelitian ini menggunakan metode deskriftif kualitatif. Dengan metode ini digunakan untuk menguraikan permasalahan yang dibahas secara jelas dan komprehensif. Pengumpulan data teoritis menggunakan teknik kajian pustaka dengan mengambil data melalui kegiatan membaca berbagai literatur yang relevan dengan kajian penelitian yang dilakukan. Data dikumpulkan untuk dianalisis kemudian disajikan dalam hasil dan pembahasan agar dapat dibuat kesimpulan. 


\section{Hasil Penelitian dan Pembahasan}

a. Dilatasi Waktu Berdasarkan Perspektif Sains

Dilatasi waktu merupakan konsekuensi dari teori relativitas khusus yang dikemukakan oleh Albert Einstein pada tahun 1905. Jika seorang pengamat dalam suatu roket mendapatkan selang waktu antara dua kejadian dalam roket itu $t_{0}$, orang dibumi mendapatkan bahwa selang waktu tersebut lebih panjang, yaitu $t$. Kuantitas $t_{0}$ yang ditentukan oleh kejadian yang terdapat pada tempat yang sama dalam kerangka acuan pengamatnya disebut selang waktu proper antara kejadian itu. Bila diamati dari bumi, kejadian yang menandai permulaan dan akhir selang waktu itu terjadi pada tempat yang berbeda sehingga akibatnya selang waktunya kelihatan lebih panjang dari pada waktu proper. Efek ini disebut dilatasi (Pemuaian) waktu (Beiser, 1983).

Dalam mengemukakan terori relativitas khusus, Eintein menyatakan bahwa waktu pengamatan antara pengamat yang diam dengan pengamat yang bergerak relatif terhadap kejadian adalah tidak sama. Selang waktu yang diukur oleh jam yang relatif bergerak terhadap kejadian dengan jam yang diam terhadap kejadian, waktu yang diukur jam yang bergerak lebih besar dibandingkan waktu yang diukur oleh jam yang diam terhadap kejadian. Peristiwa ini disebut dilatasi waktu atau pemuaian waktu (Suharyanto, 2009).

Akibat penting postulat Einstein dan transformasi Lorent adalah bahwa selang waktu antara dua kejadian yang terjadi pada tempat yang sama dalam suatu kerangka acuan selalu lebih singkat dari pada selang waktu antara kejadian sama yang diukur dalam kerangka acuan lain yang kejadiannya terjadi pada tempat yang berbeda (Budiyanto, 2008).

Secara matematis dilatasi waktu dapat dinyatakan dengan:

$$
t=\frac{t^{\prime}}{\sqrt{1 \frac{v^{2}}{c^{2}}}}
$$

Dengan :

$t=$ selang waktu yang terukur oleh pengukur yang bergerak relatif

$t^{\prime}=$ selang waktu yang terukur oleh pengukur yang diam

$v=$ kelajuan relatif pengukur $(\mathrm{m} / \mathrm{s})$

$c=$ kecepatan cahaya dalam ruang hampa $\left(3 \times 10^{8} \mathrm{~m} / \mathrm{s}\right)$

Berdasarkan ketiga sumber tersebut dapat disimpulkan bahwa dilatasi waktu merupakan perbedaan waktu akibat gerak relative. Dilatasi waktu adalah konsekuensi dari teori relativitas khusus di mana dua pengamat yang bergerak relatif terhadap satu sama lain akan mengamati bahwa waktu pengamat lain berbeda. Dengan kata lain bahwa waktu akan berjalan lebih cepat menurut pengamat yang diam relatif terhadap titik acuan, sedangkan bagi pengamat yang bergerak relatif terhadap titik acuan maka waktu akan bergerak lebih lambat.

b. Dilatasi Waktu Berdasarkan Perspektif Al-Qur'an

Ada beberapa ayat Al-Qur'an yang menjelaskan tentang dilatasi waktu jauh sebelum teori dilatasi waktu relativitas Einstein ditemukan, diantaranya sebagai berikut:

"Dan mereka meminta kepadamu (Muhammad) agar azab itu disegerakan, padahal Allah sekali-kali tidak akan menyalahi janji-Nya. Dan Sesungguhnya sehari di sisi Tuhanmu adalah seperti seribu tahun menurut perhitunganmu," (QS. Al-Hajj: 47).

"Dia mengatur segala urusan dari langit ke bumi, kemudian (urusan) itu naik ke-Nya dalam satu hari yang kadarnya (lamanya) adalah seribu tahun menurut perhitunganmu," (QS As-Sajdah: $5)$.

"Para malaikat dan Jibril naik (menghadap) kepada Tuhan, dalam sehari setara lima puluh ribu tahun," (QS. Al-Ma'arij: 4).

"Allah berfirman, Berapa tahunkah lamanya kamu tinggal di bumi? Mereka menjawab: Kami tinggal (di bumi) sehari atau setengah hari, maka tanyakanlah kepada mereka yang menghitung. Allah berfirman: Kamu tinggal (di bumi).hanya sebentar saja, jika kamu benar-benar mengetahui," (QS. Al-Mu'minun: 112-114). 
"Dan engkau akan melihat gunung-gunung, yang engkau kira tetap ditempatnya. Padahal ia berjalan (seperti) awan berjalan. (itulah) ciptaan Allah yang mencipta dengan sempurna segala sesuatu. Sungguh, Dia Maha mengetahui apa yang kamu kerjakan," (QS. An-Naml: 88).

Mengingat perbedaan waktu yang sangat besar, periode alam semesta yang dinyatakan dalam beberapa ayat Al-Qur'an tersebut sangat cocok dengan perkiraan ilmuwan. Sebagai contoh, periode satu hari menurut Al-Qur'an dapat dianggap sebagai seribu tahun waktu dibumi. Maka sudah jelas bahwa waktu memang sangat relatif. Waktu menurut ukuran manusia berbeda dengan waktu menurut Allah swt. waktu untuk ukuran manusia didapat dengan perhitungan yang dilakukan pada peredaran bulan terhadap bumi dan peredaran bumi terhadap matahari. Relativitas waktu ini sangat tepat memberikan cara pandang tentang alam semesta yang berlangsung miliaran tahun silam. Dengan demikian, semua penjelasan itu menunjukkan bahwa sebelum Einstein menemukan teori relativitas, Al-Qur'an sudah sejak dulu menjelaskan fenomena tersebut. Hanya saja, manusia pada zaman dulu belum dapat menjabarkan hal tersebut.

Pandangan Islam sejatinya menghadirkan cara pandang sains bermula dari penghayatan yang mendalam terhadap Kitab suci dan keinginannya yang kuat untuk beribadah kepada Allah SWT. secara sempurna. Peradaban Islam bukanlah peradaban yang mendidik generasi untuk menjadi pemakai rumus, namun mendorong untuk menghayati ragam peristiwa dan fenomena, mengkritisi warisan rumus, memperbaiki bahkan mengembangkan rumus baru yang lebih baik. Hal ini juga berlaku kepada teori dan konsep terkait wujud alam. (Supraha, 2018).

Satu "hari" menurut manusia terjadi selama 24 jam yang terjadi di bumi dan hanya berlaku secara lokal saja atau hanya berlaku dibumi saja. Namun, di alam semesta pada waktu yang lain dan pada kondisi yang lain, satu "hari" dapat didefinisikan dengan periode waktu yang jauh lebih panjang. Seperti yang digunakan oleh NASA untuk menjelajahi galaksi, bukan menggunakan waktu dibumi melainkan menggunakan waktu tahunan cahaya.

c. Penerapan Model POE2WE Dalam Pembelajaran Fisika Berbasis Video Materi Dilatasi Waktu

Pembelajaran berbasis video pada masa pandemi Covid-19 memang menjadi pilihan bagi pengajar dalam proses pembelajaran selain dengan menggunakan media virtual conference. Pembelajan berbasis video sangat perlu dikembangkan agar proses pembelajaran dapat dilakukan secara efektif, efisien dan menyenangkan. Tentu saja perlu peran ekstra dari seorang guru agar bisa mengemas video pembelajaran menjadi lebih menyenangkan dan tidak membosankan bagi peserta didik, terutama dalam pembelajaran fisika yang seakan-akan menjadi salah satu mata pelajaran yang dianggap sulit oleh siswa. Dengan memilih model pembelajaran yang tepat dan memilih media yang tepat bisa menjadi jawaban dari tantangan seorang pengajar dalam menciptakan pembelajaran yang menyenangkan. Menurut Nana, dkk (2020) Model pembelajaran POE2WE dapat menjadikan siswa sebagai subjek di dalam pembelajaran. Siswa aktif dalam menemukan suatu konsep melalui pengamatan atau eksperimen secara langsung, bukan dari menghafal buku materi maupun penjelasan dari guru. Model ini memungkinkan siswa aktif dalam proses pembelajaran, memberikan kesempatan kepada siswa untuk mengkonstrukssi pengetahuannya, mengkomunikasikan pemikirannya dan menuliskan hasil diskusinya sehingga siswa lebih menguasai dan memahami konsep yang akan berdampak pada peningkatan prestasi belajar siswa.

Langkah-langkah pembelajaran fisika materi dilatasi waktu berbasis video menggunakan model POE2WE sebagai berikut:

1. Prediction

Tahap prediction merupakan tahap pertama dalam pembelajaran menggunakan model POE2WE, pada tahap ini siswa memprediksi permasalahan yang berkaitan dengan materi dilatasi waktu. Dalam tahap ini disisipkan ilustrasi dan pertanyaan stimulus dalam video pembelajaran yang dibuat terkait materi dilatasi waktu untuk mengetahui pemahaman awal siswa terkait materi dilatasi waktu

2. Observation

Pada tahap ini siswa dapat membuktikan secara langsung prediksi mereka melalui kegiatan observasi, kegiatan observasi menggunakan media virtual laboratorium yang telah disiapkan alamat linknya atau Q-R Code yang disisipkan dalam video agar siswa dapat mengaksesnya untuk menguji hipotesis yang telah meraka buat. Dalam video juga bisa dilampirkan LKS sebagai pedoman siswa dalam melakukan observasi, LKS tersebut disimpan 
dalam Google Drive kemudian guru dapat membagikan link LKS tersebut agar dapat diakses oleh siswa.

3. Eksplanation

Pada tahap ini guru berperan untuk mengkonfirmasi atau memberi tahu jawaban yang benar terkait kegiatan observasi yang telah dilakukan. Penjelasan didalam video terkait konsep dan contoh soal dilatasi waktu.

\section{Elaboration}

Pada tahap ini siswa dapat menghubungkan teori dari materi dilatasi waktu dengan kehidupan sehari-hari. Peran guru disini yaitu mendorong siswa untuk menentukan penerapan konsep dilatasi waktu dalam kehidupan sehari-hari dan menerapkan nilai religiusnya. Guru bisa memberikan stimulus berupa pertanyaan terkait penerapan konsep dilatasi waktu dalam kehidupan sehari-hari dan memberikan contoh penerapan konsep didalam video yang dibuat.

5. Write

Pada tahap ini siswa menuliskan kesimpulan dari serangkaian kegiatan pembelajaran yang telah dilakukan berkenaan dengan materi dilatasi waktu. Pada tahap ini siswa dapat merefleksikan pemahaman yang telah mereka dapat kedalam bentuk tulisan. Tentunya saja dalam video disisipkan intruksi untuk siswa agar menuliskan kesimpulan dari serangkaian kegiatan pembelajaran yang telah dilakukan.

6. Evaluation

Tahap ini merupakan tahap untuk mengukur sejauh mana siswa memahami materi yang telah dipelajari dalam tahap sebelumnya. Guru dapat memberikan soal atau tugas yang harus dikerjakan oleh siswa dalam video pembelajaran yang dibuat.

\section{Simpulan}

Berdasarkan penelitian diatas dapat disimpulkan bahwa menurut teori sains dilatasi waktu merupakan perbedaan waktu akibat gerak relative. Dilatasi waktu adalah konsekuensi dari teori relativitas khusus di mana dua pengamat yang bergerak relatif terhadap satu sama lain akan mengamati bahwa waktu pengamat lain berbeda. Dengan kata lain bahwa waktu akan berjalan lebih cepat menurut pengamat yang diam relatif terhadap titik acuan, sedangkan bagi pengamat yang bergerak relatif terhadap titik acuan maka waktu akan bergerak lebih lambat. Waktu menurut ukuran manusia berbeda dengan waktu menurut Allah swt. waktu untuk ukuran manusia didapat dengan perhitungan yang dilakukan pada peredaran bulan terhadap bumi dan peredaran bumi terhadap matahari. Relativitas waktu ini sangat tepat memberikan cara pandang tentang alam semesta yang berlangsung miliaran tahun silam. Dengan demikian, semua penjelasan itu menunjukkan bahwa sebelum Einstein menemukan teori relativitas, Al-Qur'an sudah sejak dulu menjelaskan fenomena tersebut. Hanya saja, manusia pada zaman dulu belum dapat menjabarkan hal tersebut. Allah telah berikan petunjuk kepada manusia lewat kita suci Al-Qur'an. Dalam pembelajaran fisika materi dilatasi waktu berbasis video sangat cocok diterapkan model POE2WE sehingga video pembelajaran tidak membosankan dan tidak berpusat pada guru sebagai sumber informasi.

\section{Referensi}

Budiyanto, J. (2008). Fisika Untuk SMA/MA. Jakarta: Pusat Perbukuan Departemen Pendidikan Nasional

Jumini, S. (2015). Relativitas Einstein terhadap Waktu Ditinjau dari Al-QuranSurat Al-Ma'ârij Ayat 4. Syariati, 1(02, Nov), 213-232.

Mahmudah, I. R., Makiyah, Y. S., \& Sulistyaningsih, D. (2019). Profil keterampilan proses sains (KPS) siswa SMA di Kota Bandung. DIFFRACTION, 1(1).

Mundilarto. (2010). Penilaian Hasil Belajar Fisika. Yogyakarta: P2IS UNY 
Nana, N., \& Surahman, E. (2019). Pengembangan Inovasi Pembelajaran

Digital Menggunakan Model Blended POE2WE di Era Revolusi Industri 4.0. In Prosiding SNFA (Seminar Nasional Fisika dan Aplikasinya) (Vol. 4, pp. 82-90).

Nana, S., Akhyar, M., \& Rochsantiningsih, D. (2014). The development of Predict, Observe, Explain, Elaborate, Write, and Evaluate (POE2WE) Learning Model in Physics Learning at Senior Secondary School. Development, 5(19).

Nana, N., \& Surahman, E. (2019). Pengembangan Inovasi Pembelajaran Digital Menggunakan Model Blended POE2WE di Era Revolusi Industri 4.0. In Prosiding SNFA (Seminar Nasional Fisika dan Aplikasinya) (Vol. 4, pp. 82-90).

Suharyanto. (2009). Fisika untuk SMA dan MA Kelas XII. Jakarta: Pusat Perbukuan Departemen Pendidikan Nasional.

Supraha, D. W. (2018). Pemikiran George Sarton \& Panduan Islamisasi Sains. Depok: Yayasan Adab Insan Mulia.

Wartono. 2003. Strategi Belajar Mengajar Fisika. Malang: JICA 